\title{
ECODESENVOLVIMENTO: UMA ABORDAGEM SOB O CONTRIBUTO DE IGNACY SACHS
}

\section{ECODEVELOPMENT: AN APPROACH UNDER THE CONTRIBUTION IGNACY SACHS}

\author{
${ }^{1}$ Daiana Felix de Oliveira \\ ${ }^{2}$ Luciana de Vasconcelos Gomes Monteiro
}

\section{RESUMO}

O presente ensaio traz uma abordagem do Ecodesenvolvimento, sob o contributo de Ignacy Sachs. O objetivo do artigo, é apresentar a perspectiva desta temática, a partir do livro autobiográfico A terceira Margem: em busca do ecodesenvolvimento. A desenvoltura apregoada por Sachs oferece um contexto ao desenvolvimento, sob o paradigma de que os aspectos econômicos não devem estar dissociados das questões sociais e ambientais. $\mathrm{Na}$ oportunidade, é considerado o suporte da preservação do meio ambiente como uma responsabilidade para com as presentes e futuras gerações. Enceta uma correlação entre o crescimento econômico e o planejamento, num contexto socialmente inclusivo em harmonia com o meio ambiente. Ao dispor de sutis apontamentos sobre o ecodesenvolvimento, pretende-se despertar para uma realidade que requer planejamento, bem como, responsabilidade para com o fator desenvolvimento (econômico, social, político, cultural), enquanto atributo essencial para a compreensão de um desenvolvimento sustentável.

Palavras-chave: Crescimento econômico sustentado, Planejamento, Desenvolvimento sustentável

\begin{abstract}
This essay brings an approach to Ecodevelopment under the contribution of Ignacy Sachs. The purpose of the article is to present the perspective of this issue, from the autobiographical book - The third margin: in search of eco-development. The vaunted ease by Sachs provides a context for the development, under the paradigm that economic aspects should not be dissociated from the social and environmental issues. On this occasion it is considered the environmental preservation of support as a responsibility to present and future generations. Initiates a correlation between economic growth and planning, in a socially inclusive environment in harmony with the environment. To have subtle notes on ecological development, we intend to wake up to a reality that requires planning, as well as responsibility towards the development factor (economic, social, political, cultural), as an essential attribute for understanding sustainable development.
\end{abstract}

keywords: Sustained economic growth, Planning, Sustainable development

\footnotetext{
${ }^{1}$ Graduanda em Pedagogia pelo Centro Universitário de Várzea Grande -UNIVAG,Mato Grosso, (Brasil). Email: tutortreinamentos@gmail.com

2 Mestranda em Direito pelo Centro Universitário de João Pessoa -UNIPÊ, Paraiba, (Brasil).
} 


\section{INTRODUÇÃO}

Este ensaio faz uma análise interpretativa do ecodesenvolvimento a partir do livro autobiográfico: A Terceira Margem: em busca do ecodesenvolvimento, do economista e sociólogo polonês Ignacy Sachs, publicado em 2009 pela Companhia das Letras.

Estudioso mundialmente conhecido pelas suas obras e participações em eventos sobre o desenvolvimento socioeconômico e questões ecológicas, Sachs é considerado o criador do conceito de Ecodesenvolvimento, que defende o crescimento econômico inserido no contexto do desenvolvimento social e proteção ao meio ambiente. O termo "ecodesenvolvimento" foi mencionado pela primeira vez por Maurice Strong, na Conferência Internacional sobre o Meio Ambiente promovida pela ONU em Estocolmo, no ano de 1972.

A tese difundida por Sachs dá um novo contexto ao desenvolvimento, com o paradigma que os aspectos econômicos não devem estar dissociados dos problemas sociais e ambientais das cidades. A questão ética fundamental presente nesse contexto denota um desenvolvimento voltado para as reais necessidades sociais da população, que se referem à melhoria na qualidade de vida e o cuidado com a preservação do meio ambiente como uma responsabilidade para com as futuras gerações.

Nesse sentido, o autor desenvolveu a hipótese que existem cinco pilares da sustentabilidade do ecodesenvolvimento: sustentabilidade social, econômica, ecológica, territorial e cultural. A dimensão Social se refere à valorização da redução das diferenças sociais, a busca do desenvolvimento em sua multidimensionalidade; a Econômica envolve a manutenção da capacidade produtiva dos ecossistemas, está baseada na captação e gestão eficientes dos recursos, com investimentos público e privado; a Ecológica compreende a preservação dos recursos naturais enquanto base da biodiversidade; a Territorial se refere a distribuição espacial dos recursos das populações e das atividades, uma configuração urbana e rural equilibrada; por conseguinte, a Cultural está voltada ao respeito pelas especificidades culturais, identidades e tradições das comunidades locais.

No primeiro capítulo será feito um breve histórico sobre a vida de Ignacy Sachs, sobre sua trajetória no mundo acadêmico, os países por onde passou, onde estudou e trabalhou, os eventos que participou, até se tornar um dos nomes mais conhecidos mundialmente no campo das questões ligadas a economia e ao meio ambiente.

No segundo capítulo, tratar-se-á dos aspectos conceituais do termo ecodesenvolvimento, bem como da sua difusão nos ditos países de "Terceiro Mundo", e especificamente, no Brasil. 
Nos terceiro e quarto capítulos, adentrar-se-á a questão do desenvolvimento propriamente dita. Iniciar-se-á o terceiro capítulo destacando o direito ao desenvolvimento, apontando este, como um direito universal e inalienável, que integra o rol dos direitos humanos fundamentais. Em seguida, será apresentada a estreita relação entre o desenvolvimento e o planejamento, para logo mais, demonstrar alguns aspectos da visão de Ignacy Sachs em relação ao desenvolvimento na América Latina.

O quarto capítulo intitulado "Um brado em razão da crise", tentará de forma despretensiosa, demonstrar os caminhos apontados por Sachs para se alcançar um desenvolvimento sustentável.

\section{QUEM É IGNACY SACHS?}

Ignacy Sachs nasceu na Polônia em 1927, de onde sua familia teve que sair para fugir do Nazismo e da política racial, no início da segunda guerra mundial. Eles foram para Romênia, de lá para França onde viveram por um ano, passaram pela Espanha, Portugal até chegarem ao Brasil e se instalarem no Rio de Janeiro, período em que estava com 14 anos de idade. No Brasil, conheceu sua esposa Viola, também polonesa que veio ao país em situação familiar semelhante a sua, com quem teve três filhos, tendo a última nascida na Índia durante o período do seu doutorado. O jovem casal ingressou juntos na Universidade Cândido Mendes no Rio de Janeiro, ele no curso de economia e ela no de literatura americana.

Foi contratado pelo serviço cultural da embaixada polonesa, onde participou ativamente do desenvolvimento das relações diplomáticas entre o Brasil e a Polônia, conheceu vários intelectuais e artistas brasileiros. Junto com sua esposa elaborou o primeiro dicionário polonêsbrasileiro, que foi publicado anos mais tarde em Varsóvia, e é comercializado ainda hoje.

Em 1954, decide voltar para a Polônia, que naquele momento é tida como socialista, começa a trabalhar no instituto polonês das relações internacionais, lança alguns livros sobre a América Latina e, apoiado pelo célebre economista Michal Kalecki, ganha vasta projeção como um dos primeiros especialistas em "economias em desenvolvimento" da Polônia socialista. (GENTIL, 2011, p. 270)

Ele vai para a Índia em 1957 a serviço da embaixada polonesa e lá passa três anos, quando cursa o doutorado na Universidade de Nova Délhi. Sua tese é publicada em quatro países (Índia, Polônia, Brasil e Egito) e em dois idiomas, inglês e polonês. Após esse período, retorna à Polônia onde continua seus trabalhos e estudos, até 1968 quando a política anti-semita do governo o forçou a deixar o país. Em seguida, vai para a França, ensinar na École Pratique de Hautes Études - EPHE de Paris - que mais tarde se tornará a École des Hautes Études en 
Sciences Sociales - EHESS (Escola de Estudos Superiores em Ciências Sociais) fundada por Sachs em 1985. O diretor na época era o grande historiador e seu amigo Ferdinand Braudel. A partir de então, o nome de Ignacy Sachs passa a ser difundido por todo o mundo como defensor do crescimento econômico inserido no contexto do desenvolvimento social e proteção ambiental, demonstrado nas suas participações em eventos dessa temática e nas suas obras publicadas:

Desde então, a reputação de Sachs nos meios intelectuais do mundo inteiro é inabalável. Ele participa dos mais importantes fóruns internacionais sobre o desenvolvimento socioeconômico e as questões ecológicas: I Colóquio Internacional sobre o meio ambiente em Tóquio (1970), Conferência das Nações Unidas sobre o meio ambiente em Estocolmo (1972), Encontro em Cocoyoc (1974), Conferência Mundial no Rio de Janeiro (1992) e outros eventos do mesmo porte; é convidado, como perito e consultor pelos governos e organismos internacionais (Conselho Nacional das Ciências e da Tecnologia do Peru, PNUD, FAO, Fundação Internacional para um outro desenvolvimento - Fipad, Ministério do Meio Ambiente do Brasil), faz palestras em numerosas universidades, inclusive na da ONU, organiza o Centro de estudos sobre o Brasil contemporâneo em Paris, chega a conhecer pessoalmente Maurice Strong, Serge Antoine, Fernando Henrique Cardoso, Clemens Heller e outros grandes políticos e intelectuais do século XX. (GENTIL, 2011, p. 270)

Esse autor de formação acadêmica em economia se auto intitula ecossocioeconomista, pois acredita que a ecologia, a sociologia e a economia são conceitos que estão integrados, sendo assim, o desenvolvimento ambiental não pode ser dissociado das questões sociais e econômicas.

\section{ECODESENVOLVIMENTO: ASPECTOS CONCEITUAIS}

Ignacy Sachs é considerado o criador do conceito do ecodesenvolvimento. Esse vocábulo surgiu pela primeira vez nos corredores da Conferência de Estocolmo em 1972, pronunciada por Maurice Strong. A palavra chamou a atenção de Sachs para algo que já havia sido suscitado no seu íntimo ao longo da sua trajetória acadêmica até aquele momento, mais precisamente dois anos antes, quando participou do primeiro colóquio internacional sobre o meio ambiente como desafio às ciências sociais em Tóquio, no ano de 1970. Ele afirma que naquele evento captou pela primeira vez, o elo profundo que une a problemática do meio ambiente e a do desenvolvimento. Daí, foi aberta "uma caixa de Pandora de perguntas: como reintegrar ao campo do socioeconomista o substrato físico dos processos sociais, os fluxos da energia e da matéria, quando Marx e Durkheim nos convidavam a abstraí-los?”. (SACHS, 2009, p. 230) 
Em meados da década de 1970 existiam duas posições extremas em confronto, a respeito das relações entre o meio ambiente e o desenvolvimento econômico. De um lado estavam os partidários do crescimento selvagem, os quais acreditavam que primeiro deveria haver o desenvolvimento econômico para depois, se pensar no meio ambiente. Em oposição direta estavam os chamados "zegistas" (partidários do ZEG - Zero Economic Growth), que defendiam a proteção ao meio ambiente em detrimento de zero crescimento demográfico e material, e por fim, os partidários do estacionamento de qualquer crescimento. Diante desses conflitos, Sachs defendia que não se poderia parar o crescimento enquanto houvesse pessoas pobres no mundo e imensas desigualdades sociais; mas é necessário um "outro crescimento para outro desenvolvimento". Porquanto, "os objetivos do desenvolvimento são sempre sociais, há uma condicionalidade ambiental que é preciso respeitar, e finalmente, para que as coisas avancem, é preciso que as soluções pensadas sejam economicamente viáveis". (SACHS, 2009, p. 232)

$\mathrm{O}$ conceito de ecodesenvolvimento surge em resposta a esse conflito de opiniões divergentes, colocando-se como uma proposta de um novo estilo de desenvolvimento, representando uma espécie de "terceira via", sendo uma alternativa ao debate estabelecido entre a proposta do "crescimento zero" de um lado, e aqueles que reivindicam o "direito ao crescimento" dos países do Terceiro Mundo, do outro. (FERNANDEZ, 2011, p. 110)

Esse novo paradigma do desenvolvimento demonstra uma preocupação com os aspectos econômicos, porém, não dissociados dos problemas sociais e ambientais das cidades. Existe uma questão ética fundamental nesse contexto, de que o desenvolvimento deve estar voltado para as necessidades sociais mais abrangentes, que se referem à melhoria da qualidade de vida da maior parte da população, e o cuidado com a preservação do meio ambiente como uma responsabilidade para com as futuras gerações.

Três grandes pensadores influenciaram Ignacy Sachs na formação do conceito de ecodesenvolvimento: Benjamin Franklin com a sua concepção de que fazer ecodesenvolvimento é, saber aproveitar os recursos potenciais do meio, e adequar de forma prudente a utilização dos recursos ambientais às necessidades do homem; Mahatma Gandhi e seu enfoque na problemática ética; e René Dubos, que prega a simbiose entre a humanidade e a terra, para ele é necessário abandonar o falso critério de artificialidade ou naturalidade de um ecossistema e, não só postular um impossível um patamar de igualdade entre o homem e a natureza, mas encontrar os meios socialmente úteis e ecologicamente prudentes de valorizar os recursos naturais.

Para muitos estudiosos da área, o conceito de Ecodesenvolvimento é sinônimo de Desenvolvimento Sustentável, sendo muitas vezes substituído por este. Mas essa afirmação 
desagrada Sachs, pois ele que durante vários anos trabalhou na formação de um conceito adequado para o Ecodesenvolvimento, acredita, portanto, que este é o termo mais adequado. Como é possível perceber no trecho citado por Montibeller (1993, p. 133): "Trata-se, portanto, o Ecodesenvolvimento, de um projeto de Civilização, na medida em que evoca: um novo estilo de vida; conjunto de valores próprios; conjunto de objetivos escolhidos socialmente; e visão de futuro". Nesse sentido, Fernandez (2011, p. 110) parafraseando Hauwermeiren (1998, p. 7) afirma que os conceitos de ecodesenvolvimento e de desenvolvimento sustentável estão no cerne do campo teórico da Economia Ecológica, que é considerada por alguns como a ciência da "gestão da sustentabilidade". Na visão de Montibeller (1993), o ecodesenvolvimento deve ser desenvolvido na concepção de solidariedade entre a atual e as futuras gerações:

O Ecodesenvolvimento pressupõe, então, uma solidariedade sincrónica com a geração atual, na medida em que desloca a lógica da produção para a ótica das necessidades fundamentais da maioria da população; e uma solidariedade diacrônica, expressa na economia de recursos naturais e na perspectiva ecológica para garantir às gerações futuras as possibilidades de desenvolvimento. (MONTIBELLER, 1993, p. 133)

De acordo com o ensinamento de Sachs, o ecodesenvolvimento pode ser concebido como um projeto de civilização, que propaga um novo estilo de vida, com um conjunto de valores próprios, com objetivos sociais e um olhar voltado para o futuro.

\subsection{O ECODESENVOLVIMENTO NO TERCEIRO MUNDO}

Ao aprofundar seus estudos sobre o ecodesenvolvimento no Terceiro Mundo, Sachs se debruçou sobre o crescimento desordenado da região urbana, sobre a questão da proliferação das favelas e das precárias condições dos bairros periféricos. Diante desse quadro, concluiu que é preciso confrontar essa situação a fim de promover condições dignas de moradia para as pessoas que ali habitam. Contudo, reconhece que "a problemática da favela é extremamente complexa" e merece ser tratada como tal. Para o pesquisador, o Estado possui imensa responsabilidade na "organização socioeconômica" das cidades e, portanto, deve dar apoio às populações locais. Para promover o ecodesenvolvimento a uma população urbana pobre e marginalizada, a solução é a autoconstrução assistida, "que podia se tornar o eixo de uma dinâmica desenvolvimentista, contanto que se resolvessem os inúmeros problemas legais, em especial o da propriedade da terra". (SACHS, 2009. p. 281-282)

Nesse contexto, Sachs afirma que toda cidade é um ecossistema, como tal, seus recursos devem ser valorizados em benefício da população, e não, degradados, desperdiçados ou mal 
utilizados, como acontece na maioria das vezes. As cidades devem enriquecer o seu ecossistema, de forma que os seus recursos sejam administrados com responsabilidade, como por exemplo, diminuindo o consumo de energia, evitando o desperdício da água encanada, promovendo o aproveitamento da água da chuva, etc.

Nos países do Terceiro Mundo é difícil mensurar o grau de urbanização das cidades, pois muitas estatísticas são mascaradas por diferentes critérios. Sendo assim, a urbanização isolada não pode ser indicador de desenvolvimento. Faz-se necessário empregar o termo "urbanização" de forma mais rigorosa e delimitada, avaliada juntamente com outros critérios como, a quantidade de pessoas que tem moradia, um emprego decente e possibilidades reais do habitante daquela região exercitar a sua cidadania.

O desenvolvimento não pode ser reduzido apenas a crescimento econômico. É necessário que o desenvolvimento seja aplicado em duas visões simultâneas: dando um enfoque no crescimento, "que nos remete ao crescimento do PIB, à acumulação de capital, ao progresso técnico, à produtividade crescente do capital", e outro, no trabalho, utilizando o emprego e o auto emprego como porta de entrada, observando "em que medida o processo de desenvolvimento favorece a inserção social pelo trabalho decente de todos os que sentem a necessidade e o desejo de trabalhar". Essas duas ópticas devem ser articuladas, combinadas e conciliadas em um planejamento flexível. (SACHS, 2010, p. 33-34)

A visão de Sachs a respeito do desenvolvimento se coaduna com a de José Eli da Veiga quando esse último prega que, para se atingir o desenvolvimento é primordial que sejam removidas "as principais fontes de privação da liberdade", elenca, assim, a pobreza e a tirania, além da falta de oportunidades econômicas e políticas sociais viáveis, da negligência dos serviços públicos, e a intolerância ou a interferência de Estados repressivos na vida do cidadão. (VEIGA, 2010, p. 34)

\subsection{O ECODESENVOLVIMENTO NO BRASIL}

O Brasil se tornara a principal "terra de pesquisas" de Ignacy Sachs por vários motivos: por ter vivido no país com sua família, pelas inúmeras amizades construídas, pelos alunos e pelo modo de ser e viver do brasileiro, que segundo o autor, possui uma simpatia irradiante e uma vivacidade singular. Mas além desses motivos, Sachs assevera que o "Brasil representa um caso típico de mau desenvolvimento, ainda mais consternador na medida em que possui trunfos poderosos para decolar". (SACHS, 2009, p. 292)

Diante da afirmação acima destacada, o pesquisador pergunta: O século XXI pertencerá ao Brasil? Ou ele se contentará em permanecer o país do eterno futuro que tarda a chegar? Para 
Sachs, o Brasil possui as suas raízes envenenadas pelo passado colonial que continua a disseminar práticas clientelistas e atravancar o sistema político brasileiro. Embora, o país disponha de excelentes condições para se desenvolver plenamente tanto na esfera social como ambiental.

Após a Conferência de Estocolmo em 1972, e o aprofundamento nas pesquisas sobre o ecodesenvolvimento, o Brasil começou a desempenhar um papel primordial na disseminação do conceito. O primeiro projeto de ecodesenvolvimento no país nasceu em meados de 1978, em um vilarejo chamado Juramento, no Estado de Minas Gerais. Embora o projeto tenha fracassado, Sachs teve oportunidade de participar de outras experiências que foram muito proveitosas. Como consequência dessas, o pesquisador concluiu que não é possível discutir o desenvolvimento sem que se tenha um conhecimento da ecologia cultural do lugar.

A sua relação com Brasil se intensificou a partir dos anos 1980, no período da ditadura militar, e se fortaleceu, ainda mais, por volta de 1985 com o retorno da democracia ao país. Nesse período teve contato com várias figuras de renome do cenário político brasileiro, destacando-se o ex-presidente da República, Fernando Henrique Cardoso com quem trabalhou, no seu primeiro governo, como consultor do Ministério do Meio Ambiente.

Por oportuno, a seguir, perceber-se-á alguns apontamentos a respeito do desenvolvimento.

\section{DIREITO AO DESENVOLVIMENTO: UM REGISTRO}

Ao reconhecer o desenvolvimento ${ }^{1}$ enquanto um processo de mudança, crescimento, evolução, bem como, vislumbrar sempre uma conotação positiva em relação ao mesmo, entende-se, de bom alvitre, acrescer conteúdo a respeito do direito ao desenvolvimento. Pois bem,

[...] o direito ao desenvolvimento situa-se hoje no contexto dos direitos humanos fundamentais, positivado, inclusive, na ordem internacional.

\footnotetext{
1 Cf: Convém rastrear o significado do termo desenvolvimento. Ao averiguar o mesmo encontra-se, "Ato ou efeito de desenvolver(-se). Crescimento, progresso". (AURÉLIO, 2010). A ideia que advém é que "desenvolvimento pressupõe crescimento a partir de um determinado status quo, e tem subjacente a ideia de progresso. Da mesma forma, se formos desmembrar o seu vocábulo iremos nos deparar com a seguinte análise:". (Registra-se que no texto original, é feito um esboço sob o qual aparece o termo: "Figura 1: Etimologia da Palavra Desenvolvimento (...) Adaptação de Diniz (2006, p.33)". Aqui, tentar-se-á transmiti-lo em forma de texto), qual seja: "Latim: in volvere. Português: Des (prefixo de negação ou ausência) - en (Movimento para dentro) - volver(Reverter, Virar) - mento (Sufixo que indica ação). Nesta análise, é possível perceber que, com a junção dos elementos que compõem a palavra desenvolvimento, formaremos algo que poderia ser expresso como: "sem movimento para reverter a ação" ou ainda "sem envolvimento". Is so nos remete a uma conclusão de que é preciso algo para gerar o movimento e/ou envolvimento. Entretanto, o que seria esse algo? Para qual direção o movimento se conduz? Envolver para quê? As respostas para essas questões dependem do contexto no qual se aplica a palavra. (...)". (SANTOS; BRAGA. et al. 2012. p. 45-46).
} 
Exemplo disso é a Resolução 41/128 da Assembleia Geral das Nações Unidas, de 04 de dezembro de 1986, que aprovou a Declaração sobre o Direito ao Desenvolvimento. Da mesma forma, na Declaração e Programa de Ação de Viena, adotada consensualmente em plenário, pela Conferência Mundial dos Direitos Humanos, em 25 de junho de 1993, afirma-se o direito ao desenvolvimento como um direito universal e inalienável, constituindo parte integral dos direitos humanos fundamentais. [...] No contexto do Estado brasileiro, o direito ao desenvolvimento é qualificado como objetivo fundamental da República (art. $3^{\circ}$, da CF). [...] o desenvolvimento é visualizado não apenas como um processo socioeconômico, mas, também, como instrumento de promoção dos valores humanos e da cidadania. (ALBUQUERQUE; BELO, et al. 2012, p. 7-9)

Em consonância com a desenvoltura a que se propõe o presente ensaio, percebe-se o grau de acuidade e de proteção que se encontra o (tão almejado) desenvolvimento. Feito esse registro, segue-se em tom de harmonia.

\subsection{SENSIBILIDADE}

Ao fazer uma retrospectiva, Sachs tem a sensação de ter cumprido um trajeto marcado pela unidade de propósito e por uma progressão. Por este aporte, identifica que o desenvolvimento é um conceito processual que reside no tempo e surte efeitos sobre espaços distintos.

Como uma placa que sinaliza um trajeto, Sachs alerta que as ciências sociais delineadas com sensibilidade ajudam a transmitir perguntas certas. Contudo, as respostas a essas perguntas só podem vir da práxis. Desconfia das ciências sociais quando postas a serviço de governos autoritários.

Em sede de aparte, ou mesmo correlação, cabe suscitar o pensamento de Amartya Sen que, ao compor sobre algumas privações de liberdade relata que, a um grande contingente de pessoas são negados a liberdade política e os direitos civis essenciais. Com base nisso é afirmado, por alguns, que a negação de tais direitos é fonte de incentivo ao crescimento econômico e é saudável para o desenvolvimento a curto prazo. Estes, ergueram a bandeira dos sistemas políticos mais autoritários como vantagem na promoção do desenvolvimento econômico; a chamada "tese de Lee". Na realidade, não há sustentação pujante neste sentido, e são ínfimos os indícios para corroborar esta “tese". "As evidências empíricas indicam veementemente que o crescimento econômico está mais ligado a um clima econômico mais propício do que a um sistema político mais rígido". (SEN, 2010, p. 30)

Pois bem, mesmo desconfiante das ciências sociais instrumentalizadas (considerando as experiências históricas e os estragos resultantes de dogmatismos), Sachs pensa que elas têm 
bastante a oferecer para a articulação das normas. Aponta, então, o desenvolvimento como conceito normativo por reunir um conjunto de valores predominantes em uma sociedade axiologia. Dito de outro modo, o desenvolvimento vai servir de instrumento de avaliação das trajetórias percorridas e de suporte para elaborar os projetos que devem melhorar essas trajetórias; cumpre, pois, dupla função.

Despontará sempre uma ideia de desenvolvimento envolvendo a pluridisciplinaridade e o comparatismo. Registre-se o fato de que mesmo sob uma base teórica construída por um economista, não se acolhe a ideia de dependência única entre o desenvolvimento e os saberes econômicos. (SACHS, 2009a)

O breve introito deste capítulo cultivou o liame, o fio de Ariadne, para dar continuidade ao Planejamento e Desenvolvimento.

\subsection{PLANEJAMENTO E DESENVOLVIMENTO}

Seguramente, desenvolvimento e planejamento estão bem próximos. Para o tema em comento, essa noção torna-se vívida quando, por exemplo, recorta-se o cenário pós Segunda Grande Guerra. Instante em que havia um acordo, praticamente universal de unir três ideias centrais para expulsar os estilhaços do Holocausto e barrar definitivamente sua volta (o pleno emprego, o Estado protetor e o planejamento). Havia divergência concernente às ideias, sobretudo em relação ao modus operandi.

Há alguns relatos de planejamento que não lograram êxito, a e.g. do que ocorrera na União Soviética e na Polônia. Em relação àquela, o insucesso pôs fim a um modelo centralizado, autoritário e ineficaz, cujo esboço não havia lugar para imprevistos de qualquer ordem (políticos, econômicos). Em apenso, a função mais importante do referido planejamento era reservada às instâncias políticas.

Nesse ínterim, na Polônia, trabalhos cuidadosos foram realizados para alterar a metodologia desse planejamento, todavia, inércias políticas dificultaram que bons instrumentos fossem corretamente aplicados.

Por tais razões, visualizou-se que para ter êxito, o planejamento seria excelente parceiro para a democracia.

Em Paris, através de oportuno contato com planejadores de empresas americanas, tornou-se contundente a opção planejamento. Até porque, se as grandes empresas planejam é intolerável imaginar um Estado privando-se deste caractere. A experiência mais arrojada deste intercâmbio, resultara na promoção do diálogo social com olhares a definir as orientações da política. (SACHS, 2009a) 
Percebe-se pelo deslinde que, Sachs sempre vai remeter a um ou a outro local envolvendo critérios plurid isciplinares e comparatistas.

Aproximando-se geograficamente, segue a ótica do mesmo, em relação à América Latina.

\subsection{A VISÃO DE SACHS EM RELAÇÃO À AMÉRICA LATINA: ALGUNS ASPECTOS}

Com destreza, Sachs volta os olhos aos acontecimentos extraindo dos mesmos uma acentuada carga de seiva. Percebe-se isto nas linhas e entrelinhas de seus escritos. Assim, já fora mencionado alhures alguns informes de outros países, agora, entra em cena, sorrateiramente, a Argentina. (SACHS, 2008)

Pois bem, este Estado aponta como um caso forte de "pobreza na abundância" e de subdesenvolvimento em situações não belicosas, que originou de uma argamassa de dependência excessiva de recursos externos, de confiança exacerbada no Consenso de Washington e de má governança (SACHS, 2008). Sobre este último critério, é uma missão árdua visualizá-lo sem fazer correlação ao Brasil. Todavia, tenta-se seguir.

De início, registra-se que, o colapso da Argentina representou o fim do estatismo e da economia de comando. Estes dois eventos, apesar dos deslizes, se tornam uma espécie de sirene que ecoa, sempre, àqueles erros, a ponto de anunciar que se avance, sem que o botão vermelho seja acionado. Apesar das falhas, ainda assim é possível extrair algumas vantagens do Estado, mercado e comunidade, e ousar combiná-las a fim de organizar a correção das mesmas. (SACHS, 2008)

Para que isso aconteça, é necessário um Estado "renovado", planejador e visionário. O que requer num primeiro instante, a articulação de espaços de desenvolvimento do nível local ao transnacional (imagina-se a nível local que, o item desenvolvimento ganha impulso no compromisso com a administração do município, ocorre que, grande parte (dos gestores) se "contenta" com os recursos do Fundo de Participação dos Municípios (FPM), sem desenvolver/efetivar projetos ou mesmo políticas que venham a incrementar o orçamento e/ou o desenvolvimento - isso, a nível de Brasil); num segundo instante, estaria a promoção de parcerias entre todos os atores interessados - um acordo negociado de desenvolvimento sustentável; e ainda, a sintonia de metas sociais, ambientais e econômicas, via planejamento estratégico e gerenciamento cotidiano da economia e da sociedade, objetivando um equilibrio entre as diferentes sustentabilidades (social, cultural, ecológica, ambiental, territorial, econômica e política) e as eficiências. (SACHS, 2008) 
Observa-se que, os objetivos do desenvolvimento vão além do desdobramento da riqueza material. O crescimento é uma condição fundamental, mas não se torna suficiente para se obter o progresso. (SACHS, 2008)

No contexto que surgiu, a ideia de desenvolvimento suscita a análise e a reparação de desigualdades passadas, criando uma relação capaz de preencher a disparidade civilizatória entre as minorias ricas e a maioria pobres. (SACHS, 2008)

Ademais, uma outra possibilidade de enfrentar o desenvolvimento seria reconceituá-lo em termos de apropriação efetiva das três gerações de direitos humanos, uma vez que, igualdade, liberdade e solidariedade estão inseridos no conceito de desenvolvimento, com efeitos a longo prazo para que a inspiração econômica em relação ao desenvolvimento se diferencie do "economismo redutor". Dito de outro modo, no lugar de maximizar o crescimento do Produto Interno Bruto (PIB), o alvo se torna promover a igualdade e fomentar a vantagem daqueles que experimentam condições miseráveis, de forma a reduzir a pobreza. (SACHS, 2008)

O conceito de desenvolvimento sustentável acresce a sustentabilidade ambiental à dimensão da sustentabilidade social, baseada no duplo imperativo ético que corre ao mesmo tempo com a geração atual e de solidariedade para com as gerações futuras. Um olor em relação à essência do art. 225 da CRFB/88.

Pois bem, tal desenvoltura permite atentar a critérios de tempo e espaço. Instiga ainda a buscar soluções multifacetadas, eliminando o crescimento obtido a custos mesquinhos (sociais e ambientais). Algumas estratégias de curto prazo, conduzem ao "crescimento ambientalmente destrutivo, mas socialmente benéfico", ou em ordem inversa (SACHS, 2009b). Apresenta-se assim, os cinco pilares do desenvolvimento sustentável:

Social - devido a perspectiva de "fratura" social que paira de forma tenebrosa sobre diversos lugares;

Ambiental - com a sua dupla dimensão (sustentação da vida enquanto provedor de recursos e "recipiente" para a disposição de resíduos);

Territorial - em relação à distribuição espacial dos recursos das populações e das atividades;

Econômico - representativo de instrumento relevante para efetivar as programações;

Político - a "governança democrática" é suporte necessário para a realização das metas; a liberdade exerce fator diferencial. Neste segmento, Amartya Sen denota contundente defesa, “[...] a visão da liberdade aqui adotada envolve tanto os processos que permitem a liberdade de ações e decisões como as oportunidades reais que as pessoas têm dadas as suas circunstâncias 
pessoais e sociais" (SEN, 2010, p. 32). Ou seja, a análise das liberdades participa dos elementos constitutivos necessários.

Para caminhar de mãos dadas com esse quinteto, muito tem que ser posto em prática. Possivelmente, adotando estratégias nacionais diferenciadas, mas complementares em relação ao Norte; estratégias de desenvolvimento endógenas e inclusivas em relação ao Sul, com base na biomassa, perfeitamente adequada aos países tropicais; acordo Norte/Sul a respeito do desenvolvimento sustentável, aumentando criteriosamente o fluxo de recursos do Norte para o Sul; um sistema internacional de impostos (pedágios para o uso de oceanos e espaços aéreos) por falar em oceanos, lembra-se, in casu, do Brasil, da Agência Nacional das Águas (ANA), um caso à parte; gerenciamento das áreas globais de uso comum. (SACHS, 2008)

Analisa-se com cautela as perspectivas a curto prazo. Contudo, enquanto enfrentam a batalha política na frente global, os países latino-americanos, poderiam entoar o mote do desenvolvimento sustentável para versar suas estratégias domésticas. Uma espécie de resiliência para o desenvolvimento.

Impende, neste cenário, fazer uma analogia com as políticas implementadas por alguns países da Europa e da Ásia no primeiro momento da reconstrução que sucedeu à Segunda Grande Guerra, decerto que, propostas para as reformas das instituições e adoção do comércio justo provavelmente não surgirão por ação dos países do G7 + a Rússia, satisfeitos com o status em que se encontram. Certamente, virão do diálogo entre países periféricos e das suas conversas com alguns setores da sociedade civil dos países centrais. (SACHS, 2008)

Portanto, vislumbra-se uma propositura sistematizada. Uma espécie de análise em relação ao antes, durante e depois.

Diante do que fora supracitado, ressaltando abordagens multidisciplinares e comparativas, inclusive, de modo mais abrangente, não se vê como a avaliação crítica dos itinerários percorridos pelos vários países pode desconectar o conceito de desenvolvimento e de seu inverso - o mau desenvolvimento. Ampliou-se assim, para demonstrar que sem esses modelos (padrões), impossibilita fazer julgamentos de valor. (SACHS, 2009a)

Remontando o caso do Brasil (comparatismo), durante o período de 1944 a 1975 (Trinta Gloriosos), o crescimento se deu de forma rápida e socialmente positiva, todavia, foi um lapso marcado por uma feroz degradação do meio ambiente. Pode-se, também, conceber um crescimento sustentado e respeitoso do meio ambiente, porém, catastrófico no plano social por ser insuficiente em criar oportunidades de trabalho decente. Logo, nenhuma dessas categorias de crescimento deveria ser confundida com o desenvolvimento. (SACHS, 2009a) 
Nesse diapasão, o termo desenvolvimento convém adequar-se às soluções de um crescimento econômico sustentado, socialmente inclusivo e em harmonia com o meio ambiente (SACHS, 2009a). O cerne é basicamente este.

\section{UM BRADO EM RAZÃO DA CRISE}

Eliminado o fator surpresa, em 2004, Sachs fora convidado para participar da décima primeira Conferência das Nações Unidas para o Comércio e o Desenvolvimento (UNCTAD), em São Paulo, cuja abordagem se tratara de um estudo intitulado "Da armadilha da pobreza ao desenvolvimento includente", sobre os países menos desenvolvidos (SACHS, 2009a). Pois bem, quatro anos depois, este contexto é apresentado em um dos capítulos do livro Desenvolvimento: includente, sustentável, sustentado. (SACHS, 2008). A essência é mantida; a insistência nos firmamentos de um novo ciclo de desenvolvimento rural nos países tropicais. (SACHS, 2009a)

Os relatórios da UNCTAD sobre os países menos desenvolvidos (PMDs) disponibilizam uma avaliação fidedigna da situação. Sejam quais forem as suas diferenças (histórica, geopolítica, densidade demográfica), todos eles encontram-se encarcerados por uma armadilha de pobreza estrutural, em razão do notável subdesenvolvimento de suas atividades produtivas, atrelado a um ambiente internacional de insucesso e pela omissão dos países ricos enquanto assistentes. Assim, os PMDs são vítimas diretas da não integração pela globalização. (SACHS, 2008)

Contudo, apesar das desvantagens, esses países têm um potencial para reunir planos de desenvolvimentos nacionais, includentes, sustentáveis e sustentados. O chamado “desenvolvimento a partir de dentro", segundo, O. Sunkel, 1992 citado por SACHS (2008). Uma espécie de resiliência para o desenvolvimento.

No mesmo raciocínio, convém observância ao trinômio biodiversidade-biomassabiotecnologia que credita futuros pretensos, uma vez que, as biotecnologias intervêm tanto para surpreender os rendimentos da biomassa como para estender o leque dos produtos derivados (contributivos na alimentação para homens e animais, adubos verdes, farmacopeia, cosméticos); neste sentido, a produção de energia remonta a um relevante fator, ou seja, o aumento na sua utilização pode estar atrelado à redução no consumo do petróleo e seus derivados. Neste aspecto, os países tropicais contemplam benefícios por sua biodiversidade e pelos climas favoráveis à produção de biomassa. (SACHS, 2009a)

O relevante é investir nessa via de modo que esses países atentem aos anseios da crise social, proporcionando, também, oportunidades de trabalho decente. 
Importa, neste sentido, tecer algumas linhas em relação à roupagem que deve ser vestida no trabalhador em relação ao fator desenvolvimento; uma etiqueta que só pode ser apregoada através do trabalho (sentido lato) decente. Do contrário, a atividade laboral também pode divergir da ideia de desenvolvimento - trabalho não digno.

Neste sentido, considera-se, fundamentalmente, a Declaração de 1986 da Organização das Nações Unidas (ONU), por prover a orientação internacional na delimitação do desenvolvimento, bem como o direito a este. Marcam presença, de igual modo, as diretrizes da Organização Internacional do Trabalho (OIT), em sua causa de estabelecer conceito universal e simétrico para o labor realizado em condições dignas (CECATO, 2011). Adentra-se na seara do meio ambiente de trabalho seguro e saudável condizente com os fundamentos elencados na CRFB/88.

Ademais, o desenvolvimento rural socialmente includente e em sintonia com o meio ambiente requer vazões intensivas em conhecimentos e mão de obra. No pensar de Sachs, a maior categoria social do planeta.

Adiante, outro estudo fora desenvolvido relativo aos efeitos do aumento do preço do petróleo para os PMDs.

Recorda-se por ora, acerca do texto de Alan Greenspan, quando tratara a respeito da duradoura escassez de energia; pelo teor do mesmo, depreende-se que o escol dos lucros arrecadados pelo alavanco dos preços de petróleo (envolvendo especialmente os países produtores) não é encaminhado para o desenvolvimento, mas concentrado e dilapidado pelas elites no poder. Ao identificar, dentre outros sintomas, Alan pontua que, "Se a história for boa guia, o petróleo será substituído por alternativas menos dispendiosas, bem antes do esgotamento das reservas convencionais". (GREENSPAN, 2008, p. 443)

Decerto que, a história também demonstra versatilidades, a exemplo da substituição do carvão, da madeira. Lança-se, justamente, os debates sobre a opção dos biocombustíveis. O Brasil, neste aspecto é terra de solos fecundos.

\subsection{CAMINHOS PARA O DESENVOLVIMENTO SUSTENTÁVEL}

Pela conjuntura delineada, percebe-se a necessidade de "repensar o Estado desenvolvimentista" (SACHS, 2009a). O que desemboca em uma análise dos principais contextos para, assim, traçar os percursos em direção ao desenvolvimento.

Neste segmento, entra em cena, ou melhor, volta a compor a cena, o desenvolvimento includente, cujo eixo é o trabalho decente, em marcante sintonia com a OIT. Assim, corrobora o fato de que não basta proporcionar vultuosas oportunidades de trabalho, sem que se atenda 
aos requisitos (fundamentais) apregoados pela Carta Maior, dentre eles, a dignidade da pessoa humana, a higidez no meio ambiente do trabalho, (Art. $1^{\text {o }}$, III, e, Art. 200, VIII, ambos da CRFB). Já que o envoltório é desenvolvimento, não há como dissociar o trabalho deste processo. Como assevera Cecato (2011, p. 29), "Em síntese, não há que se falar em desenvolvimento em todas as suas dimensões, sem nele considerar a participação do trabalhador e sua inarredável premissa: a existência de emprego.”. Acolhe-se, neste sentido, trabalhador em sentido lato, ou seja, não apenas os que guardam relação (no caso do Brasil) com a Consolidação das Leis do Trabalho (CLT). Marca presença, neste âmbito, a máxima da distinção entre crescimento econômico e desenvolvimento.

Ao analisar o Brasil, Sachs atenta ao fato de que o país deve privilegiar em seus investimentos as indústrias de elevado nível técnico, de modo que ocorra a modernização da estrutura produtiva e seja um suporte facilitador para a inclusão de sua economia na divisão internacional do trabalho.

Com vigor, aponta que a maior porção de empregos e autoempregos está no campo, num novo ciclo de desenvolvimento rural. Neste aspecto, o Brasil comporta a maior biodiversidade do mundo, terras ainda não exploradas, florestas tropicais, água, aquífero, climas propícios. Agregado a uma pesquisa agrônoma e biológica de nível internacional. (SACHS, 2009a). Um arcabouço, realmente, diferenciado.

Sugere-se, ainda, desenvoltura significativa para com a biodiversidade, a biomassa e as biotécnicas. Conforme observado algures.

Modo pelo qual, resta admitir a biodiversidade de forma holística e interdisciplinar, uma vez que, abarca os ecossistemas e as paisagens, além das espécies e genes, de modo que cientistas naturais e sociais contribuam juntos em prol de caminhos valorosos para o uso e benefício dos recursos naturais, de modo a atrelar conservação e aproveitamento dos recursos naturais. (SACHS, 2009b)

Em relação à biomassa, de certa forma, as principais civilizações do passado se utilizaram desta, aproveitando-a para a vida material (alimentos, fibras para vestimenta, matériaprima). O que continua ainda hoje, sendo que o ponto central é transformar o conhecimento dos povos desvendando e interpretando, com auxílio das ciências de ponta, bem como, da biologia. (SACHS, 2009b). A utilização da mesma (matéria de origem vegetal utilizada como fonte de energia) evidencia a especialidade dos sistemas produtivos artificiais, comparáveis a ecossistemas naturais. Sentido em que, a ciência moderna prestará papel imprescindível para o efetivar de tais sistemas. (SACHS, 2009b) 
Por sua vez, as biotecnologias exercerão a incumbência de alcançar as extremidades da cadeia de produção possibilitando uma ampliação na faixa de produtos dela derivados.

De outra banda, positiva via é a de disponibilizar a biotecnologia moderna para os pequenos fazendeiros, orientando-os, capacitando-os. De igual modo, desestimular o êxodo para os centros urbanos. (SACHS, 2009b; SACHS, 2009a)

Neste setor, o Ministério do Meio Ambiente está com o formato de um curso de Formação em Manejo Florestal Sustentável Integrado de Uso Múltiplo na Caatinga, na sede do Instituto Nacional do Semiárido, em Campina Grande/PB. Tem início, assim, um programa de capacitação em manejo e uso sustentável do bioma, o qual contribuirá para inserir o tema como prioritário no planejamento das ações e políticas com objetivo de promover uma economia sustentável. A iniciativa reúne os compromissos da Conferência das Nações Unidas sobre Desenvolvimento Sustentável (Rio+20), que propõe a conservação das paisagens e a recuperação de áreas degradadas. (MINISTÉRIO DO MEIO AMBIENTE, 2015)

Pois bem, esforços sejam encaminhados em prol do desenvolvimento "verde". O Brasil, in casu, apresenta uma oportunidade ímpar de alavancar etapas para atingir uma moderna civilização de biomassa, atendendo inclusive, relevância social, prudência ecológica e viabilidade econômica. Este e outros países tropicais têm diferenciadas condições de se tornarem exportadores de sustentabilidade - do desafio à oportunidade, e promissora. (SACHS, 2009b)

Assim, quer seja definido como ecodesenvolvimento ou desenvolvimento sustentável, a ideia fundamentada na harmonização de objetivos sociais, ambientais e econômicos não se modificou desde o encontro de Estocolmo; ainda é válido, para além do crescimento econômico. (SACHS, 2009b)

Pode-se registrar que o desenvolvimento sustentável reflete um sistema, é, contudo, um desafio planetário. Encomenda, pois, estratégias complementares entre o Norte e o Sul. Com pujança, os padrões de consumo do Norte são insustentáveis, ao passo que, o enverdecimento do Norte clama uma mudança endógena, uma mudança de vida, caminhando ladeada da revitalização dos sistemas tecnológicos.

José Eli da Veiga, oportunamente, traz uma passagem em que Celso Furtado pronuncia, “O mais importante é que a idéia de desenvolvimento está no cerne da visão de mundo que prevalece em nossa época. Nela se funda o processo de invenção cultural que permite ver o homem como um agente transformador do mundo". (FURTADO apud VEIGA, 2010, p. 30)

Pela essência, pelo papel do agente, que os povos não se furtem de uma positiva metamorfose. 


\subsubsection{Por uma cultura desenvolvimentista}

Sabe-se que neste início de século, a dificuldade é profunda. A história oferece em elenco de argumentações para esta afirmação. Todavia, é sobre os escombros que a constituição de novos projetos e estruturas tem que alocar. Para tanto, precisa-se de um composto de ideias que se concatenem. Assim, Sachs (2009a) indica: "Não digo que a teoria do desenvolvimento forneça respostas prontas, [...]", mas as ciências sociais, ratifica-se, cumprem uma função heurística, sobretudo, na formulação de perguntas para incentivar o debate na sociedade (práxis).

Por oportuno, a cultura do desenvolvimento deveria se enraizar como um elemento de ensino, desde o colégio.

As respostas dependerão das diferentes desenvolturas, do conjunto de valores, a questãomor não é o nível da "guerra", é como vai se sobressair, ou não, desta. É inerente a esse fundamentar das respostas, o conjunto de valores e o estilo de vida cada povo, de cada sociedade.

Envolto a esta cultura, um diferencial, é o voluntarismo responsável - não se muda tudo em um curto espaço de tempo, seria, portanto, o inverso. Só será considerado responsável se o indivíduo analisa as margens reais de liberdade que restam. (SACHS, 2009)

De qualquer forma, a política exerce forte influência no contexto social. Todavia, ante a toda uma complexidade incutida nesse âmbito, é louvável um debate político, que aspira soluções negociadas entre os partícipes do processo de desenvolvimento, que caminha rente com o amadurecimento das instituições democráticas e com a imposto pelo ritmo dos prazos eleitorais.

Destarte, a análise comparativa no tocante às trajetórias do desenvolvimento e o oposto do mesmo em relação aos diversos países é convocada a se tornar um notável instrumento de "metodologia" política, designando a seara dos debates sobre os projetos nacionais/internacionais (SACHS, 2009a), uma vez que, lida-se com direitos difusos, imbui, pois, presentes e futuras gerações.

\section{CONSIDERAÇÕES FINAIS}

Ao fazer-se jus a uma análise holística em relação ao que fora delineado, depreende-se que, Ignacy Sachs oferece um conteúdo real, acurado e relevante nesta hora do padrão ecológico.

Por este aporte, a ideia como fora lançada nesta reflexão, o surgimento do conceito, o tratamento pelo mesmo em relação ao principal teórico; perpassando pela abordagem em 
relação ao Brasil; o pontuar a respeito do direito ao desenvolvimento, o elo intrínseco deste com o planejamento.

E ainda, a sensibilidade inerente às ciências sociais na elaboração de perguntas (cujos resultados advêm da práxis); o demonstrativo das falhas em alguns países, acolhendo como recorte exemplificativo o período pós Segunda Grande Guerra, para o demonstrativo da correlação planejamento e desenvolvimento; alguns caminhos para serem trilhados e algumas partículas mais.

Convém que, dispor destes sutis apontamentos sobre o ecodesenvolvimento, tentou-se despertar para uma realidade que clama por responsabilidade, compromisso, seriedade e deslinde para com o fator desenvolvimento, sobretudo em sua versatilidade (econômico, social, político, cultural). Enquanto vertente essencial para o desenvolvimento sustentável.

Neste sentido, fazendo-se jus às palavras de Sachs, requer-se, voluntarismo responsável, por conseguinte, efetividade. Sementes foram lançadas, adubos também, a ciência de que desenvolvimento não se confunde com crescimento, oferece uma base sob a qual o constructo deverá se sobrepor.

Analisar com cautela as possibilidades a curto prazo, faz parte do processo; pode ser uma característica do "novo". Aparecem modificações, reparos, ajustes a serem providenciados. Contudo, enquanto o entrave se encontra a nível global, considera-se, de bom alvitre, o crescer inicial para dentro, o renovar, o permitir desabrochar, e isso começa pelo ser humano. Ser humano, cidadão, cidade, Estado, nação, mundo; e influencia, e (re)torna para "alimentar" o (ecos)sistema. Certamente, seja assim, um direcionamento, um "norte".

Destarte, ratifica-se que, o termo desenvolvimento convém adequar-se às soluções de um crescimento econômico sustentado, socialmente inclusivo e harmônico com o meio ambiente. Condizente, pois, com o direito ao desenvolvimento, cujo teor é intrínseco aos direitos humanos fundamentais, presente, inclusive, na ordem internacional.

\section{REFERÊNCIAS}

ALBUQUERQUE, Armando; BELO, Alexandre. et al. Desenvolvimento: aspectos sociais, econômicos e político-criminais. Curitiba: Juruá, 2012, p. 7-9.

BRASIL. Constituição (1988). Disponível em: <http://www.planalto.gov.br/ccivil_03/Constituicao/Constituicao.htm>. Acesso em: 03 de jun. de 2015 .

BRASIL. Ministério do Meio Ambiente. Disponível em: $<$ http://mma.gov.br/ind ex.php/comunicacao/agencia-informma?view=blog\&id=920>. Acesso em: 26 de maio de 2015. 
CECATO, Maria Aurea Baroni. Interfaces do trabalho com o desenvolvimento: inclusão do trabalhador segundo os preceitos da declaração de 1986 da ONU. Prima Facie, João Pessoa, v. 11, n. 20, ano 11, jan-jun., 2012.

FERNANDEZ, B. P. M. Ecodesenvolvimento, Desenvolvimento Sustentável e Economia Ecológica: Em Que Sentido Representam Alternativas Ao Paradigma De Desenvolvimento Tradicional? Desenvolvimento e Meio Ambiente, n. 23, p. 109-120, jan./jun. 2011. Curitiba: Editora UFPR. Disponível em: <ojs.c3sl.ufpr.br>. Acesso em: 11 de maio de 2015.

GENTIL, Valéria. De Ignacy Sachs, la troisième rive: à la recherche de l'écodéveloppement. A terceira margem: à procura do ecodesenvolvimento. $I n$ : Rev. Sociedade e Estado. vol. 26. $n^{\circ} .1$. Brasilia Jan./Apr. 2011. Disponível em: <http://www.scielo.br/scielo.php?script=sci_arttext\&pid=S0102-69922011000100014 . Acesso em: 11 de maio de 2015.

GREENSPAN, Alan. A era da turbulência: a aventura em um novo mundo. Rio de Janeiro: Elsevier, 2008, p. 443.

HAUWERMEIREN, S. V. Manual de economia ecológica. Santiago: Rosa Moreno, 1998. HOLANDA, Aurelio Buarque. Dicionário Aurélio da Língua Portuguesa. 5a ed. 2010.

MONTIBELLER FILHO, G. Ecodesenvolvimento e Desenvolvimento Sustentável. Conceitos e Princípios. Textos de Economia. Florianópolis, 1993, v. 4, a. 1, p. 131-142. Disponível em: <https://periodicos.ufsc.br/index.php/economia/article/viewFile/6645/6263>. Acesso em: 12 de maio de 2015.

SACHS, Ignacy. A terceira margem: em busca do ecodesenvolvimento. São Paulo: Companhia das Letras, 2009a.

SACHS, Ignacy. Caminhos para o desenvolvimento sustentável. Rio de Janeiro: Garamond, 2009b.

SACHS, Ignacy. Desenvolvimento: includente, sustentável, sustentado. Rio de Janeiro: Garamond, 2008.

SACHS, IGNACY. Estratégias de Transição para o Século XXI - Desenvolvimento e Meio Ambiente. São Paulo: Studio Nobel - Fundap, 1993.

SANTOS. Elinaldo Leal. BRAGA, Vitor. et al. Desenvolvimento: um conceito multidimensional. In: Revista Eletrônica do Programa de Mestrado em Desenvolvimento Regional da Universidade de Contestado. Ano 2, n. 1, jul. 2012, p. 45-46. Disponível em: <http://recipp.ipp.pt/bitstream/10400.22/1858/1/ART_ElinaldoSantos_2012.pdf>. Acesso em: 04 de jun. de 2015.

SEN, Amartya. Desenvolvimento como liberdade. Rio de Janeiro: Companhia de Bolso, 2010.

UNESCO-MAB.

Disponível em: $<\mathrm{http} / /$ www.unesco.org/new/pt/brasilia/naturalsciences/environment/biodiversity/biodiversity /mab-programme-in-brazil/>. Acesso em: 31 de maio de 2015.

VEIGA, José Eli da. Desenvolvimento sustentável: o desafio do século XXI. Rio de Janeiro: Garamond, 2010. 